\title{
Stage of Regional Emerging Industries of Strategic Choice Model and Its Application
}

\author{
Yong-Chun $\mathrm{Ao}^{1}$, Xia $\mathrm{Jin}^{2}$, \\ ${ }^{1)}$ Network social development research center, The Chongqing University of Posts and Telecommunications, Nanan District, \\ Chongqing, China \\ ${ }^{2)}$ The Chongqing Vocational College of Information Technology, Wanzhou District, Chongqing, China
}

\begin{abstract}
Strategic emerging industry is the key to seize the commanding heights of the economy and promote the change, the pattern of regional economic development. To develop must make a choice. Only the right choice can promote the development. However, the choice of regional strategic emerging industries is a very complicated work. Consider revising, the article makes a comprehensive selection and analysis of strategic emerging industry taking Chongqing city as an example by using the established model selection stage. Finally we selected the strategic emerging industries that being conducive to in the development of Chongqing
\end{abstract}

Keywords - Regional strategic emerging industry, phase selection, factor analysis, entropy method

\section{区域战略性新兴产业的分阶段选择模型及应用}

\author{
敖永春 $^{1}$ 金霞 $^{2}$ \\ 1) 重庆邮电大学网络社会发展问题研究中心, 南岸区, 重庆, 中国 \\ 2) 重庆信息技术职业学院，万州区，重庆，中国
}

摘 要 战略性新兴产业是抢占经济制高点, 促进区域经济发展方式转变的关键。要发展首先要选择, 只有选对了才能促进发展。 然而, 区域战略性新兴产业的选择又是一项十分复杂的工作。基于此, 文章运用建立了分阶段选择模型, 以重庆市为例进行了战略性 新兴产业的综合选择分析, 最终选择出了利于重庆发展的战略性新兴产业。

关键词 区域战略性新兴产业, 分阶段选择, 因子分析, 摘值法

\section{1. 引言}

目前, 我国主要省市地区都以国家大力推动战略性新 兴产业发展为契机, 全面制定和规划了战略性新兴产业发 展目标, 希望通过发展战略性新兴产业促进产业升级, 提 振区域经济。各省市在选择战略性新兴产业的时候, 既要 在国家战略性新兴产业的框架下, 又要注重与地区实际和 地区发展战略相匹配, 这样才有利于形成各具特色、优势 互补、结构合理的战略性新兴产业发展格局。从系统论的 观点来看, 区域经济系统是一个开放的系统。区域战略性 新兴产业是区域经济系统中至关重要的组成部分, 是区域 未来的先导产业和支柱产业, 关系着区域未来的产业结构 水平和经济增长速度, 同时区域经济系统又是更为广泛的 国民经济系统和世界经济系统的一部分。因此, 在研究时
必须要放宽眼界, 不仅要研究系统本身, 还要研究系统的 环境和背景, 以及先进技术的发展方向, 对系统有一个全 面、客观的认识。区域经济系统也是一个复杂的系统, 区 域战略性新兴产业的选择亦是一个复杂的过程。因此, 在 这个过程中, 不仅要进行科学合理的定量分析, 还要在定 量分析前后做一定的定性分析。

\section{2. 分阶段选择基本模型}

\section{1 区域分析阶段}

区域分析阶段的目的是为了区分出可能成为战略性新 兴产业的候选产业。任何一个区域在进行战略性新兴产业 选择时, 都需要对区域自身环境进行系统分析。区域战略 性新兴产业的功能是促进区域产业结构升级, 带动区域经 
济增长, 同时战略性新兴产业的成长要受到本地区要素条 件、资源禀赋和区位因素等客观条件的影响。因此, 在选 择区域战略性新兴产业前, 首先要对区域自身有一个全面 客观的了解和分析, 其中包括: 生产要素资源禀赋、产业 结构现状、区位条件等等。

\section{2 定量选择阶段}

对区域内部和外部环境进行系统客观的分析之后, 就 进入区域战略性新兴产业的选择阶段。定量选择阶段包括: 选择基准与指标的确立; 数据收集; 评价方法的选择; 指 标量化分析; 计算综合得分; 形成综合评价。本文主要是 采用因子分析法 ${ }^{[1]}$ 和熵值法 ${ }^{[2]}$ 分别以重庆市第二产业和第 三产业为例进行实证研究。

\section{3 综合评价阶段}

(1) 区域战略性新兴产业的发展是国家经济系统发展 过程中的一部分, 选择区域战略性新兴产业除了分析区域 自身情况外, 还应该客观地分析区域的外部环境, 进行区 域外部分析。一般来说需要分析一下内容: 国家宏观产业 政策与布局、经济技术发展趋势、产业区际分工、外部市 场需求结构及其变化。要结合国家的产业布局和当前技术 发展趋势, 选择区域的战略性新兴产业, 在国家统筹下发 挥自身优势, 形成区域特色产业发展集群。

（2）由于战略性新兴产业的特殊性, 研究特别是相关 数据统计都处于初级阶段, 只能以现有的统计分类为基础 进行选择, 因此需要对最后的结果进行一定的定性分析, 从现有分类中析出战略性新兴产业具体分类产业。主要是 通过将定量选择出来的产业进行细分, 在更细小的产业类 别中选出战略性新兴产业的具体产业而不仅仅是产业领 域。

\section{3. 重庆市概况以及产业结构}

\section{1 重庆市概况}

重庆作为中国最年轻的直辖市, 地处长江上游, 东邻 湖北省、湖南省, 南连贵州省, 西接四川省, 北与陕西省 接壤, 是我国东部经济发达地区和西部资源丰富地区的结 合部, 承东启西、左右传递的枢纽, 对我国经济发展的总 体发展具有重要的战略地利作用。全市总面积 82, 403 平方 公里, 是我国面积最大的直辖市, 具有对 2 亿多人口大市 场的区域辐射能力和带动力。重庆地区矿产资源十分丰富, 已发现矿产 75 种, 已探明储量 40 多种, 是全国特大城市 中矿产资源最丰富的地区之一, 主要有煤、天然气、铝土 矿、锶、锰、录、钒、钿、钡、岩盐、重晶石、萤石、石
灰石、石膏、大理石等。依托重庆 “渝新欧” 国际铁路联 运大通道、全国五大枢纽机场之一的江北国际机场, 重庆 汇集形成水、陆、空无缝连接的立体交通网络, 随着水陆 空交通的逐步完善, 重庆将成为长江上游最大的物资集散 地和贸易中转地, 成为西南地区最大的物流中心, 为战略 性新兴产业的发展提供了极为有利的条件。

\section{2 重庆市产业结构分析}

重庆市直辖以来, GDP 由 1998 年的 1602.38 亿元增加 到 2011 年的 10011.37 亿元, 现价总量翻了一番多, 年平 均增长速度达到 $15.14 \%$ 。在经济总量增长的同时, 产业结 构也发生了一定的变化。三次产业结构从1998 年 $18.8: 42.2: 39$ 变为 2011 年 8.4:55.4:36.2。第一产业比重 下降 10.4 个百分点, 第二产业比重上升 13.2 各百分点, 第三产业比重下降 2.8 个百分点。2011 年全市第二产业对 经济增长贡献率达到 73. 3\%, 比 1998 年上升 30 个百分点, 其中工业对经济增长的贡献率上升 37.1 个百分点。可见, 第二产业尤其是工业的增长成为重庆经济快速增长的主要 动力, 是促进重庆产业结构调整和推动全市经济快速、健 康、协调发展的主导力量。

重庆三次产业近 5 年持续增长, 第二产业始终保持优 势且增速同比第一、第三产业较快, 产值稳步增长。第三 产业增长趋势明显, 但在总产值中比重有所下 降. 2006-2011 年重庆市三产业产值 2011 年重庆市三次产 业增加值结构比为 8. 4:55.4:36.2, 同比 2010 年第一产业 下降 0.2 , 第二产业上升 0.4 , 第三产业下降 0.2 个百分点。 第一、第二、第三产业对生产总值的贡献率分别为 $2.7 \%$, $73.3 \% 、 24.0 \%$, 分别比 2010 年下降 0.5 个百分点, 上升 4.7 个百分点, 下降 4.2 个百分点。说明第二产业在重庆 的国民经济中的比重在不断提高, 发挥的作用在不断增强, 但结构不合理, 第三产业比重较低, 需要进行产业结构调 整。

重庆大中型企业的数量和固定资产的规模都不小, 现 在已经形成以汽车、摩托车为重点的机械工业, 以钢材和 铝材为代表的冶金工业, 以天然气、化工和医药工业为重 点的化学工业三大支柱产业。优势产业看, 规模以上工业 中, 汽车摩托车行业总产值 3273.58 亿元, 增长 $13.4 \%$, 占工业总产值 27.2\%; 装备制造业总产值 2631.79 亿, 增 长 $56.7 \%$, 占工业总产值 $21.9 \%$; 材料工业总产值 1821.88 亿元, 增长 $31.4 \%$, 占工业总产值 $15.1 \%$; 电子信息产业总 产值 2027.90 亿, 增长 $98.6 \%$, 占工业总产值的 $16.8 \%$ 。 ${ }^{[3]}$

综合以上重庆产业结构和产业状况的数据分析, 分别 对第二产业和第三产业进行了选择。从第二产业中选取煤 炭开采和洗选业、石油和天然气开采业、黑色金属矿采选 
业、有色金属矿采选业、非金属矿采选业等 27 个行业作为 候选战略性新兴产业。从第三产业中选取信息传输、计算 机服务和软件、房地产、租赁与商务服务、交通运输及仓 储和邮政、金融、文化体育与娱乐、住宿和餐饮、科学研 究及技术服务等 8 个行业作为候选战略性新兴产业。

\section{4. 重庆市战略性新兴产业的定量选择}

\section{1 指标体系的建构}

区域战略性新兴产业的选择, 不仅要遵循科学的选择 原则, 还要有合理可行的选择基准。本文将区域战略性新 兴产业选择基准确定为: 产业增长潜力、产业综合效益、 产业带动性、产业技术创新、产业资源环境和产业比较优
势基准 ${ }^{[4]}$ 。本文选择了 6 个一级指标、 15 个二级指标构建区 域战略性新兴产业选择的指标体系。由于第二产业和第三 产业的统计口径不同, 产业特性也有较大区别。因此, 针 对第二产业和第三产业分别采用不同的指标体系。表 1 是第 二产业的选择指标体系, 表2为第三产业的选择指标体系。

目前战略性新兴产业的相关统计处于起步阶段, 数据 难以获取。本文的数据主要来源于 2010-2012《重庆统计 年鉴》、2011《中国统计年鉴》和 2010 年重庆 42 部门投入 产出表, 收集了我市第二产业中 27 个、第三产业中 8 个产 业 2010 年的相关数据。由于投入产出表中的产业划分和统 计年鉴中的产业划分有一定的差异, 本文以统计年鉴的分 类为准, 同时对得到的影响力和感应度系数加以近似处理。

表1 区域战略性新兴产业选择的指标体系1

\begin{tabular}{|c|c|c|c|}
\hline \multirow{12}{*}{$\begin{array}{l}\text { 区 } \\
\text { 域 } \\
\text { 战 } \\
\text { 略 } \\
\text { 性 } \\
\text { 新 } \\
\text { 兴 } \\
\text { 产 } \\
\text { 选 } \\
\text { 择 } \\
\text { 价 }\end{array}$} & 一级指标 & 二级指标 & 计算方法 \\
\hline & \multirow{2}{*}{ 产业增长潜力 } & 工业增加值率 & 产业增加值/工业总产值 \\
\hline & & 成本费用利润率 & 产业的利润总额/成本费用 \\
\hline & \multirow{3}{*}{ 产业综合效益 } & 利税增长率 & 利税总额增量/上期利税总额 \\
\hline & & 总资产贡献率 & \\
\hline & & 全员劳动生产率 & \\
\hline & 产业带动性 & 影响力系数 & 里昂惕夫逆矩阵纵列系数的均值/全部产业 \\
\hline & \multirow{2}{*}{ 产业技术创新 } & 新产品产值比重 & 新产品产值/产业总产值 \\
\hline & & 科技经费比率 & 科技经费支出/产业增加值 \\
\hline & \multirow{2}{*}{ 产业资源环境 } & 单位产值能耗率 & 产业能源消费量/产业增加值 \\
\hline & & 三废综合利用率 & 三废排出量/总产值 \\
\hline & 产业比较优势 & 区位商 & (产业产值/该地区工业总产值)/（全国该行业产值/全国工业总产值） \\
\hline
\end{tabular}

表2 区域战略性新兴产业选择的指标体系2

\begin{tabular}{|c|c|c|c|}
\hline \multirow{8}{*}{$\begin{array}{l}\text { 区 } \\
\text { 域 } \\
\text { 战 } \\
\text { 略 } \\
\text { 性 } \\
\text { 兴 } \\
\text { 产 } \\
\text { 业 } \\
\text { 选 } \\
\text { 评 } \\
\text { 价 }\end{array}$} & 一级指标 & 二级指标 & 计算方法 \\
\hline & \multirow{3}{*}{ 综合效益 } & 劳动生产率 & 产业增加值/从业人数 \\
\hline & & 产值规模 & 产业增加值/地区 GDP \\
\hline & & 产业增长 & 产业增加值增量/前期增加值 \\
\hline & \multirow{2}{*}{ 带动性 } & 影响力系数 & 里昂惕夫逆矩阵纵列系数的均值/全部产业 \\
\hline & & 感应度系数 & 里昂惕夫逆矩阵横行系数的均值/全部产业 \\
\hline & \multirow[t]{2}{*}{ 比较优势 } & 产业贡献率 & 增加值增量/区域增加值增量 \\
\hline & & 市场占有率 & 产业增加值/全国该行业的增加值 \\
\hline
\end{tabular}

4.2 重庆市第二产业的因子分析

将收集和整理的数据进行标准化处理, 得到一个
$15 \times 27$ 的矩阵的形式, 行是 15 个指标, 列是 27 个候选产 业, 指标依次表示为 $\left(X_{1}, X_{2}, \cdots, X_{14}, X_{15}\right)$ 。

将处理后得到的数据, 用 SPSS 软件进行分析, 操作步 
骤 “Analyze-Data Reduction-Factor”。根据原有变量的 相关系数矩阵, 我们选取数值大于 1 的特征根, 最后得到 五个公共因子。因为前五个因子的累计贡献率达到 $80.500 \%$, 选择这五个主因子原有信息的丢失量较少, 可以 反映出大部分信息, 用因子分析来评价备选产业是可行的。

为了让公因子变量更加具有可解释性, 采用方差最大 正交旋转法将采用主成分分析得到的因子载荷矩阵进行旋 转, 进而得到旋转后的因子载荷矩阵。由各因子载荷大小, 我们选取载荷 $>0.5$ 的来可以提取公共因子。

根据软件得到的结果, 第一主因子的方差贡献率为 $32.086 \%$, 在 5 个主因子中最大, 在 $X_{12} 、 X_{13} 、 X_{14}$ 和 $X_{15}$ 方面有较大载荷, 反映的是产业的比较优势, 因此称为 “比 较优势因子”。第 2 个主因子的方差贡献率为 16.220 , 在 $X_{6} 、 X_{7} 、 X_{8}$ 和 $X_{9}$, 反映的是产业的创新和带动性,

因此称为 “创新及关联因子”。第 3 个主因子的方差贡献率 为 13.935 , 在 $X_{3} 、 X_{4}$ 和 $X_{5}$ 方面有较大载荷, 指标反映 的是产业的综合效益, 因此称为 “效益因子”。第 4 个主因 子的方差贡献率为 10.442 , 在 $X_{1}$ 和 $X_{2}$ 方面有较大载荷, 反映的是产业的增长潜力, 因此称为 “增长因子”。第 5 个 主因子的方差贡献率为 7.838 , 在 $X_{10}$ 和 $X_{11}$ 方面有较大 载荷, 反映的是产业对环境的影响, 因此称为 “环保因子”。

最后根据 5 个主因子的因子得分和方差贡献率加权求 和得到产业综合得分。综合得分排在前十位的产业分别为 交通运输设备制造业、烟草制品业、化学原料及化学制品 制造业、煤炭开采和洗选业、医药制造业、石油和天然气 开采业、通用设备制造业、非金属矿物制品业、黑色金属 冶炼及压延加工业、电力、热力的生产和供应业。

按 F1 排名, 依次为交通运输设备制造业、非金属矿物 制品、煤炭开采和洗选、废弃资源和废旧材料回收加工业; 按 F2 排名, 依次为化学原料及化学制品制造业、仪器仪表 及文化用品制造、医药制造、专用设备制造、通用设备制 造、电气机械及器材制造业; 按 F3 排名, 依次为烟草制品 业和石油和天然气开采业; 按 F4 排名, 依次为烟草制品业、 煤炭开采和洗选业、水的生产和供应业; 按 F5 排名, 依次 为化学原料及化学制品制造业、非金属矿物制品业、黑色 金属冶炼及压延加工业、电力、热力的生产和供应业。

\section{3 运用熵值法对重庆市第三产业的选择}

第三产业较少, 数据样本量相对也少, 很难用因子分 析方法进行定量选择, 因此采用熵值法对第三产业进行选 择。熵值法是通过固有的数据来进行权重的确定, 减少了 主观因素的影响。其主要原理是通过判断各个因素的变化 剧烈程度来确定该因素在最终目标中所占的权重。
(1)数据标准化。设 $m$ 个评价指标 $n$ 个产业的原始数据 矩阵为 $A=\left(a_{i j}\right)_{m \times n}$, 标准化后得到 $R=\left(r_{i j}\right)_{m \times n}$ 。

$$
r_{i j}=\left[\frac{a_{i j}-\min \left(a_{1 j}, a_{2 j, \ldots}, a_{n j}\right)}{\max \left(a_{1 j}, a_{2 j, \ldots}, a_{n j}\right)-\min \left(a_{1 j}, a_{2 j, \ldots}, a_{n j}\right)}\right] \times 100
$$

(2)计算第 $j$ 指标下第 $i$ 产业占该指标的权重:

$$
p_{i j}=\frac{r_{i j}}{\sum_{i=1}^{n} r_{i j}}(i=1,2, \cdots, n ; j=1,2, \cdots, m)
$$

(3)计算熵值。第 $j$ 个指标的熵为:

$$
e_{j}=-k \sum_{i=1}^{n} p_{i j} \ln p_{i j}
$$

其中, $\mathrm{k}>0, k=1 / \ln (n), e_{j} \geq 0$

(4)计算权重。第 $j$ 个指标的熵权:

$$
\omega_{j}=\frac{1-e_{j}}{m-\sum_{j=1}^{m} e_{j}}\left(0 \leq \omega_{j} \leq 1, \sum_{j=1}^{m} \omega_{j}\right)
$$

(5)线性加权计算产业的综合得分:

$$
F_{i}=\sum_{j=1}^{m} \omega_{\mathrm{j}} \mathrm{p}_{i j}(i=1,2, \cdots, n)
$$

按(1)对数据进行标准化, 本文 $\mathrm{m}=9, n=8$ 。再, 按 式(2)-(4)进行计算, 得到各指标的权重: 劳动生产率 $=0.12655$, 产值规模 $=0.102199$, 从业人员平均 $=0.117775$, 增加率 $=0.10883$, 影响力 $=0.068033$, 感应度 $=0.164063$, 区位商 $=0.083005$, 产业贡献率 $=0.14654$, 市场占有率 $=0.083005$ 。最后按式 (5) 得到重庆市 8 个第三产业的综合 得分, 并进行排序, 结果见表 3 。

表 3 产业综合得分及排名

\begin{tabular}{|l|c|c|}
\hline 产业名称 & 综合得分 & 排名 \\
\hline 金融业 & 0.302093 & 1 \\
\hline 交通运输、仓储和邮政业 & 0.136369 & 2 \\
\hline 信息传输、计算机服务和软件业 & 0.135484 & 3 \\
\hline 房地产业 & 0.127072 & 4 \\
\hline 住宿和餐饮业 & 0.10937 & 5 \\
\hline 科学研究、技术服务与地质勘查业 & 0.076764 & 6 \\
\hline 租赁与商务服务业 & 0.06628 & 7 \\
\hline 文化、体育与娱乐业 & 0.046567 & 8 \\
\hline
\end{tabular}




\section{5. 综合分析选择重庆市战略性新兴产业}

虽然文中采用了因子分析和熵值法, 都是基于实际数 据本身的处理和分析, 比较科学合理。但是, 不管什么样 的模型都是有缺点的, 本文拟通过把模型计算结果与技术 发展方向和宏观调控政策结合起来分析得到较好的弥补。

技术的发展往往会带来新的产业革命。要想选择合适 的战略性新兴产业, 就必须对科学技术发展的未来方向做 出分析和预测, 只有这样才更快地实现产业升级和产业的 长远发展。世界科学技术发展的优先领域主要表现在一下 方面。(1) 信息技术和科学将是实现经济增长的主要动力。 未来微电子、通信、计算机、软件、网络等技术发展即将 带领新的产业革命。(2) 生命科学技术。生命科学在揭示 生命本质规律以及认识和控制生命过程方面, 尤其是为农 业可持续发展和人类健康领域的问题提供了新的解决途 径。(3) 能源和环境技术。很多能源都是有限的, 而且在 开发利用过程中往往伴随着环境污染。(4) 材料科学。由 于信息技术以及生物技术的发展, 对材料的要求越来越高, 高性能材料、纳米材料、生物材料、多功能等将会对制造、 生活多方面的产生重要影响。（5）先进制造技术。制造技 术将呈现更加智能化、集成化、高密度, 为产业升级提供 重要的技术和装备基础, 同时创造高附加值的新产品。

根据定量选择中综合排名的情况, 将第二产业中的交 通运输设备制造、烟草制品、化学原料及化学制品制造、 煤炭开采和洗选、医药制造、石油和天然气开采、通用设 备制造、非金属矿物制品、黑色金属冶炼及压延加工、电 力、热力的生产和供应和第三产业中的金融、交通运输仓 储和邮政、信息传输、计算机服务和软件作为即将分析的 对象。此外, 仪器仪表及文化、专用设备制造业在 F2 上得 分较高, 排在第二位和第四位, 与第一位相差较小, 且此 因子对区域战略性新兴产业具有十分重要的意义, 因此增 加这两个共 15 个产业作为综合分析的对象。

2011 年政府组织编写了 《战略性新兴产业分类目录》, 为以后相关的统计工作奠定基础。然, 本文的数据是基于 现有的统计分类, 与战略性新兴产业分类存在差别。因此, 将上节中定量选择结果与战略性新兴产业的分类进行对接 （见表 4), 以更加清晰地展现重庆市战略性新兴产业的 选择结果。

定量选择中选出的煤炭开采和石油开采洗选, 不能作 为战略性新兴产业, 因为资源总会枯竭, 历史数据良好但 是难以持续发展。金融业虽然在国家的战略布局中并未提 及, 但现代金融业的新兴衍生产品, 对其他战略性新兴产 业的发展具有重要的支持作用, 可作为战略性新兴产业来
发展。基于前文分析, 重庆市的战略新兴产业重点应放在 高端装备制造业、新一代信息技术, 其次是新能源汽车、 生物医药和新能源领域, 在满足其他产业的发展要求之后 应适当考虑新材料和节能环保业。以现有统计分类来看, 重庆市战略性新兴产业为交通运输设备制造业、信息传输、 计算机服务和软件、化学原料及化学制品制造、医药制造、 通用设备制造和专用设备制造、金属冶炼及压延加工业、 金融, 特别是其中属于战略性新兴产业分类的部分。

表 4 战略性新兴产业对照表

\begin{tabular}{|c|c|}
\hline 战略性新兴产业 & 现有统计分类产业 \\
\hline \multirow{3}{*}{ 高端装备制造业 } & 交通运输设备制造 \\
\hline & 仪器仪表及文化、办公用机械制造业 \\
\hline & 专用设备制造业 \\
\hline \multirow{2}{*}{ 新一代信息技术 } & 信息传输、计算机服务和软件业 \\
\hline & 交通运输、仓储和邮政业 \\
\hline 新能源汽车 & 交通运输设备制造业 \\
\hline \multirow{3}{*}{ 生物医药 } & 化学原料及化学制品制造业 \\
\hline & 医药制造业 \\
\hline & 专用设备制造业 \\
\hline \multirow{2}{*}{ 新能源 } & 通用设备制造业 \\
\hline & 电力、热力的生产和供应业 \\
\hline \multirow{3}{*}{ 新材料 } & 非金属矿物制品业 \\
\hline & 黑色金属冶炼及压延加工业 \\
\hline & 通用设备制造 \\
\hline \multirow{3}{*}{ 节能环保 } & 仪器仪表及文化、办公用机械制造业 \\
\hline & 专用设备制造业 \\
\hline & 通用设备制造业 \\
\hline
\end{tabular}

\section{参考文献 (References)}

[1] Ying Hu, Jing-Lan Zhao, A study on the selection of strategic emerging industries by factors analysis," Social Science Journal, 2010, pp. 127-129.

[2] Zhen-Hua Hu, Chun-Qiu Li, Yong-Qing Xiong.Based on the "AHP-IE-PCA" combination weighting method selection model of selecting strategic emerging industries, science of science and management of science and technology, 2011, pp. 104-110.

[3] Chongqing national economic and social development statistical bulletin 2011, http://district.ce.cn.

[4] Yong-Chun AO, Xia JIN, "Study selection theory of regional emerging industries of strategic importance," The commercial era, 2012, pp. 116-118. 